CZASOPISMO INŻYNIERII LA¿DOWEJ, ŚRODOWISKA I ARCHITEKTURY JOURNAL OF CIVIL ENGINEERING, ENVIRONMENT AND ARCHITECTURE JCEEA, t. XXXIII, z. 63 (2/I/16), kwiecień-czerwiec 2016, s. 267-276

\author{
Danuta PROSZAK ${ }^{1}$ \\ Patrycja BARŁOWSKA ${ }^{2}$
}

\title{
PELET CZY WEGGIEL? \\ EKONOMICZNE ASPEKTY WYBORU PALIWA DO OGRZANIA BUDYNKU JEDNORODZINNEGO
}

\begin{abstract}
W Polsce coraz więcej użytkowników decyduje się na wspomaganie lub całkowita zamianę paliw tradycyjnych na alternatywne do ogrzewania budynków. Wybierane są paliwa, które nie szkodzą środowisku i są tańsze w zakupie. Mowa tu o energii odnawialnej: słońce, woda, wiatr jak i przetworzonej energii słonecznej pobieranej przez rośliny czyli biomasie. Jest to nie tylko związane z wymogami dotyczącymi emisji gazów oraz pyłów, które są coraz bardziej zaostrzane, ale również ma na celu zastąpienie kopalnych źródeł energii pierwotnej, energią z niskoemisyjnych źródeł odnawialnych. Wśród najważniejszych czynników, które sprawiły, że sektor energetyczny w co raz większym stopniu interesuję się wykorzystaniem biomasy, jest możliwość szybkiego przystosowania technicznego i technologicznego instalacji węglowych do spalania i współspalania biomasy [9]. Ponadto z peletu uzyskuje się energię porównywalną z tą otrzymaną z gorszej jakości węgla, otrzymuje się zerowy bilans ditlenku węgla, oraz niższą emisję zanieczyszczeń w porównaniu z węglem [8]. Jednak ciągle pozostaje duża grupa osób paląca wyłącznie węglem. Nowoczesne automatyczne piece węglowe mogą osiągać sprawność spalania 80-90\%, co sprawia, że przy relatywnie niskich cenach węgla w stosunku do innych paliw koszt ogrzewania tym rodzajem opału jest najniższy. Jednak osiągnięcie wysokiej sprawności wytwarzania ciepła jest możliwe tylko wtedy, gdy stosuje się węgiel dobrej jakości. Minusem spalania węgla jest ciemny, zanieczyszczający nasze środowisko dym, emisja pyłu i ditlenku siarki oraz powstawanie stałych produktów spalania tj. popiołu i żużla. Niniejszej publikacji porównano roczne koszty za zużyty pelet i węgiel w przypadku instalacji centralnego ogrzewania w budynku jednorodzinnym.
\end{abstract}

Słowa kluczowe: pelet, węgiel, koszty ogrzewania domu, biomasa

\section{Wprowadzenie}

Obecnie najpopularniejszym paliwem do ogrzewania domu, wciąż pozostaje węgiel. Użytkowników nie zraża kłopotliwa eksploatacja kotłów, emitowane przez nie zanieczyszczenia, a także rosnąca cena węgla. Jednak ilość pokładów

\footnotetext{
${ }^{1}$ Autor do korespondencji/corresponding author: Danuta Proszak, Politechnika Rzeszowska, Wydział Budownictwa, Inżynierii Środowiska i Architektury, Al. Powstańców Warszawy 12, 35-959 Rzeszów, tel. 17 8651699, dproszak@prz.edu.pl

2 Patrycja Barłowska, studentka, Politechnika Rzeszowska
} 
paliw kopalnianych maleje, a wymogi dotyczące emisji gazów i pyłów są coraz bardziej zaostrzane. Warto również wspomnieć o ograniczaniu emisji ditlenku węgla, powodującego efekt cieplarniany. Te czynniki zmuszają ludzi do poszukiwania innych źródeł energii. Takim źródłem jest energia odnawialna. Jest to energia pozyskiwana $z$ promieniowania słonecznego, energia wody czy wiatru, która coraz częściej zostaje zastępowana poprzez biomasę, zawierającą w sobie energię promieniowania słonecznego przekształconą podczas fotosyntezy. Produkcja peletu z biomasy jest co raz popularniejsza, gdyż można odpady rolnicze i leśne przekształcić na drogocenne paliwo. Dużym plusem na rzecz wykorzystania peletu jest jego czystość. Pelet nie brudzi, ma przyjemny zapach. Pakowany jest w poręcznie torby, a co raz wyższa sprawność kotłów na pelet, sprawia iż są dwukrotnie wydajniejsze od kotłów na węgiel. Ponadto używanie i obsługa tego typu kotłów nie wymaga codziennej pracy fizycznej, jak w przypadku kotłów na koks, brykiet czy węgiel. Przy odpowiednio dobranym koszu i podajniku zasyp granulatem następuje raz 5-7 dni.

\section{Pelet jako paliwo}

Biomasa według definicji Unii Europejskiej oznacza przydatne na rozkład biologiczny frakcje produktów, odpady i pozostałości przemysłu rolnego (łącznie z substancjami roślinnymi i zwierzęcymi), leśnictwa i związanych z nim gałęzi gospodarki, jak również przydatne na rozkład biologiczny frakcje odpadów przemysłowych i miejskich (Dyrektywa 2001/77/WE). [3] Jest to bez wątpienia najstarsze współcześnie wykorzystywane odnawialne źródło energii. Jednak nie wszystkie formy biomasy są efektem ubocznym produkcji. Aby uzyskać biomasę uprawiane są rośliny energetyczne, które cechują się znacznym przyrostem w ciągu roku oraz nie posiadają dużych wymagań odnośnie gleby można tym samym zagospodarować gleby nieurodzajne.

Najwięcej jednak biopaliw powstaje ze stałych odpadów organicznych pozyskiwanych z:

- rolnictwa (słoma, siano, drobne gałęzie pochodzące z przecinki sadów, zboże nienadające się do spożycia),

- przemysłu przetwórstwa zbożowego, tartacznego, meblarskiego, tłuszczowego (są to otręby, trociny, wióry, zrzyny, kora, makuchy rzepakowe, itp.),

- leśnictwa (drewno opałowe, zrębki, wióry, polana, trociny).

Odpady organiczne płynne i o dużej zawartości wilgoci pochodzą z:

- rolnictwa (obornik, gnojowica, gnojówka),

- przemysłu skrobiowego, cukrowniczego, przetwórstwa owocowowarzywnego, mięsnego, gorzelniczego, piwowarskiego (wytłoki, odpady z przeróbki owoców i warzyw, odpady poubojowe, itp.).

Źródła pochodzenia biomasy przedstawia rysunek 1 . Nie przetworzona biomasa jest dosyć kłopotliwym paliwem ze względu na dużą objętość, i z powodowane z tym trudności w transporcie i przechowywaniu. Dlatego też bioma- 


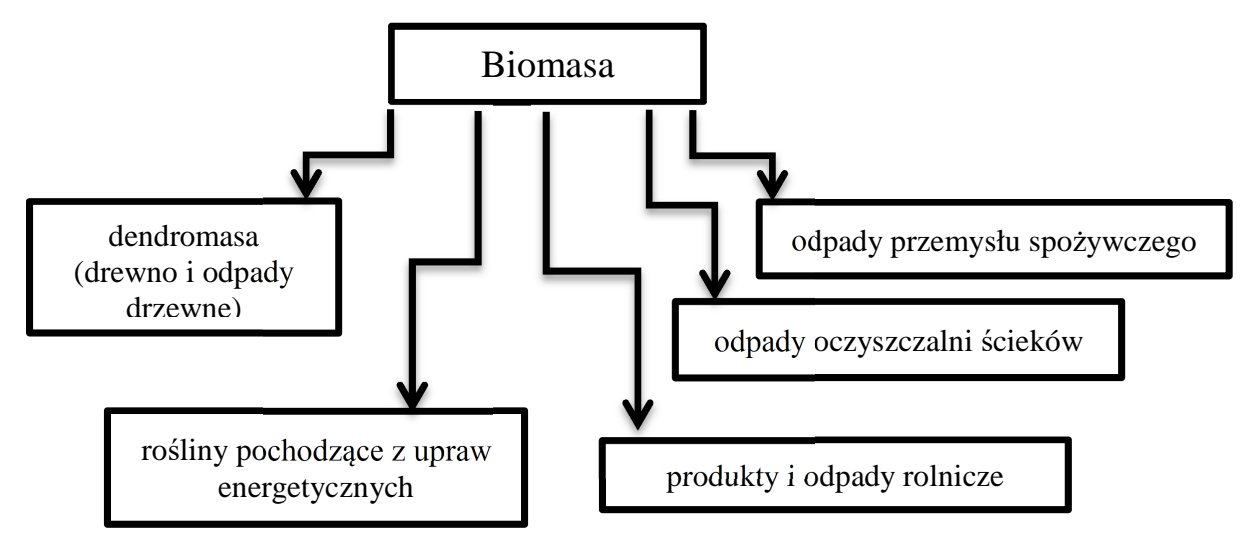

Rys. 1. Rodzaje biomasy

Fig. 1. Types of biomass

sę ujednolica się i uszlachetnia w procesie peletyzacji lub brykietyzacji. Poprzez te procesy zmniejsza się jej zawartość wody, zwiększa gęstość, dzięki czemu uzyskuje się znacznie wyższą wartość opałową w przeliczeniu na jednostkę objętości.

Surowcem do produkcji peletu i brykietu może być praktycznie każdy rodzaj roślin. Pelety i brykiety powstają poprzez sprasowanie surowca pod wysokim ciśnieniem, bez udziału chemicznych substancji klejących. Substancją spajającą jest lignina zawarta w biomasie, która w procesie peletyzacji i brykietowania pod wpływem wysokiego ciśnienia nagrzewa się i przyjmuje półpłynną postać, dzięki czemu można ją dowolnie formować. Najcenniejszym i najbardziej kalorycznym materiałem są trociny drzewne, ścinki i wióry. Pelet drzewny jest jednym z najbardziej popularnych biopaliw, służących do ogrzewania domu. Wytwarzany jest w $100 \%$ z naturalnych składników. Jest to czyste, sprasowane drewno, w którym nie ma żadnych dodatków ani substancji lepiących. Dzięki temu zawarta w surowcu energia, zostaje silnie zagęszczona, dając paliwo o bardzo dobrych właściwościach energetycznych [2]. Wartość opałowa peletu wynosi 16,5-18 MJ/kg, wilgotność waha się w granicach 7-12 \%, natomiast gęstość wynosi około $1200 \mathrm{~kg} / \mathrm{m}^{3}$. Średnica granulatu zawiera się pomiędzy $6-8 \mathrm{~mm}$ a długość od $10-30 \mathrm{~mm}$. Zaletą spalania peletu jest znikoma ilość popiołu, jaka powstaje podczas spalania. Stanowi ona zaledwie ok. $1 \%$ masy drewna i dodatkowo może być użyta, jako naturalny nawóz. Warto również wspomnieć, że jest to paliwo odnawialne, co oznacza, że ditlenek węgla, który wytwarzany jest w procesie spalania, pochłaniają rośliny podczas wzrostu w danym cyklu. Dzięki czemu można stwierdzić, że podczas spalania peletu otrzymujemy zerowy bilans ditlenku węgla, a także nie powoduje dużej ilości emisji ditlenku siarki [10].

Główne zalety peletu widoczne z punktu widzenia użytkowników, to:

- ekologia - paliwo odnawialne,

- duża wydajność energetyczna, 
- relatywnie niska cena,

- czystość, brak toksyczności,

- łatwość magazynowania.

Natomiast, warto również pamiętać o:

- zapobieganiu marnotrawstwu oraz zagospodarowaniu odpadów,

- zagospodarowaniu nieużytków oraz terenów przemysłowych przez rośliny energetyczne,

- powstawaniu nowych miejsc pracy, dzięki rozwojowi rolnictwa [4].

W Polsce pelet zyskuje coraz większą popularność. Stosowany jest nie tylko w kotłach przydomowych, które ogrzewają pomieszczenia i wodę, ale również w hotelach czy szkołach. Zyskuje również zastosowanie w nowoczesnych, automatycznych kominkach, które nie wymagają instalacji kominowych, a także w ciepłowniach miejskich czy gminnych. Idealnie sprawdza się w elektrociepłowniach, które muszą ograniczać emisję ditlenku węgla, pyłów i innych szkodliwych związków do atmosfery [6].

Warto wspomnieć, że Polska jest jednym z największych na świecie producentów i eksporterów mebli. Przemysł drzewny stanowi bardzo dużą część naszej gospodarki - podczas wyrobu mebli, generowana jest znaczna ilość trocin, które przerabiane są na ekologiczny pelet. Spadek produkcji widoczny na rys. 2 na przełomie 2012 i 2013 roku, spowodowała zbyt duża podaż zielonych certyfikatów. Ze wstępnych danych wynika, że w 2014 r. konsumpcja pelet drzewnych w UE wzrosła do ok. $20 \mathrm{mln}$ ton. Było to możliwe głównie dzięki zwiększonemu importowi. Największymi eksporterami netto pelet drzewnych na świecie w ubiegłym roku były Stany Zjednoczone (3,9 mln ton), Kanada (1,6 mln ton), Łotwa (1,2 mln ton) oraz Rosja ( $0,88 \mathrm{mln}$ ton) [5].

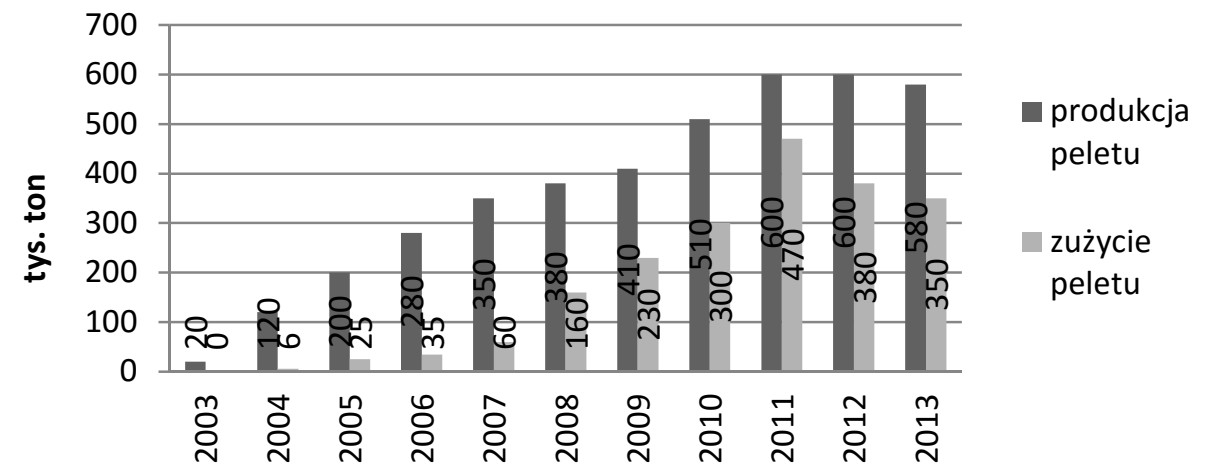

Rys. 2. Produkcja i zużycie peletu w Polsce w latach 2003-2012 (opracowano na podstawie [5])

Fig. 2. Pellet production and consumption in Poland in the years 2003-2013 (on the basis of [5]) 


\section{Właściwości węgla kopalnianego}

Węgiel kopalniany stanowi około 90 \% światowej energii. Na terenie Polski występują znaczne ilości złoża, dlatego jest on powszechnie stosowany. Używanie węgla jest ekonomiczne, co związane jest nie tylko z jego wartością opałową, ale również $\mathrm{z}$ ceną. Wartość opałowa węgla kamiennego waha się od 16,7 do $29,3 \mathrm{MJ} / \mathrm{kg}$ i jest ona silnie zależna od składu węgla - wilgotności, zawartości siarki oraz popiołu.

Innym rodzajem węgla jest węgiel brunatny, który ze względu na niższą kaloryczność niż węgiel kamienny (max. $21 \mathrm{MJ} / \mathrm{kg}$ ), odgrywa niewielką rolę z gospodarce energetycznej. Właśnie ze względu na małą kaloryczność oraz dużą zawartość wody, nie opłaca się go transportować, więc spalany jest najczęściej w pobliskich elektrowniach [7].

Tabela 1. Porównanie składu i wartości opałowej węgla kamiennego i węgla brunatnego

Table 1. Comparison of the composition and calorific value of coal and lignite

\begin{tabular}{|c|c|c|c|c|c|c|}
\hline $\begin{array}{c}\text { Rodzaj } \\
\text { paliwa }\end{array}$ & $\begin{array}{c}\text { Węgiel } \\
\mathbf{C} \\
\mathbf{\%}\end{array}$ & $\begin{array}{c}\text { Wodór } \\
\mathbf{H} \\
\mathbf{\%}\end{array}$ & $\begin{array}{c}\text { Tlen } \\
\mathbf{0} \\
\mathbf{\%}\end{array}$ & $\begin{array}{c}\text { Siarka } \\
+ \\
\text { azot } \\
\mathbf{S + N} \\
\mathbf{\%}\end{array}$ & $\begin{array}{c}\text { Wartość opałowa } \\
\mathbf{M J} / \mathbf{k g}\end{array}$ & $\begin{array}{c}\text { Części lotne } \\
\mathbf{\%}\end{array}$ \\
\hline Węgiel kamienny & 82 & 5 & 12 & 0,8 & 29 & 35 \\
\hline Węgiel brunatny & 70 & 5 & 24 & 0,8 & 21 & 50 \\
\hline
\end{tabular}

Mimo wielu zalet węgla, takich jak wspomniana wcześniej cena, czy wartość opałowa, jak również jego dostępność oraz łatwość transportu, w porównaniu do np. paliwa gazowego, istnieją również jego wady. Podstawową niedogodnością jest, to, że nie jest to paliwo ekologiczne, ponieważ podczas spalania emituje wiele szkodliwych substancji do atmosfery tj.: duże ilości pyłu w którym zawarte są metale ciężkie (w tym ołów), wielopierścieniowe węglowodory aromatyczne (w tym benzo(a)piren), tlenki siarki, tlenki azotu, tlenek węgla [7]. Ponadto powstają produkty stałe spalania: popiół i sadza. Spalanie węgla przyczynia się do zwiększenia efektu cieplarnianego i kwaśnego deszczu. Dodatkowo wydobycie węgla $\mathrm{z}$ roku na rok jest coraz bardziej kosztowne, ponieważ pozyskuje się go z głębiej leżących pokładów.

\section{Porównanie zużycia węgla i peletu w ciągu roku dla budynku jednorodzinnego}

Obliczenia wykonano dla domu jednorodzinnego o powierzchni użytkowej równej 130,68 $\mathrm{m}^{2}$, przystosowanego do potrzeb minimum czteroosobowej rodziny. Jest to budynek wolnostojący, o jednej kondygnacji nadziemnej - parter, niepodpiwniczony, z poddaszem nieużytkowym, kryty dachem wielopołacio- 
wym. Wnętrze podzielone jest na trakty o zróżnicowanej funkcji. Trakt środkowy to strefa komunikacji: zaczynając od wejścia głównego przez wiatrołap do przedpokoju. W tej strefie znajduje się również kotłownia. Dwie pozostałe części budynku jednorodzinnego to strefy funkcjonalne. Po lewej stronie sytuuje się strefa dzienna: kuchnia, spiżarnia, toaleta, salon z jadalnią oaz taras. Natomiast druga strona, to strefa nocna, w której znajdują się trzy pokoje sypialne oraz łazienka. Budynek znajduje się w miejscowości Rzeszów, dla którego przyjęto założenia dla III strefy klimatycznej.

Projektowe obciążenie cieplne budynku wynosi 7460,05 W, natomiast zapotrzebowanie na energię (wg certyfikatu energetycznego) pierwotną 9548kWh/rok, oraz końcową $10767 \mathrm{kWh} /$ rok. Obliczenia wykonano dla węgla o kaloryczności $29 \mathrm{MJ} / \mathrm{kg}$ oraz peletu o kaloryczności 17,5 MJ/kg.

Ciepło uzyskane z $1 \mathrm{~kg}$ paliwa w ciągu $1 \mathrm{~h}$ :

$$
\mathrm{Q}_{\mathrm{u}}=\frac{\mathrm{W}_{\mathrm{u}}}{3600}
$$

gdzie: $Q_{u}$ - ciepło uzyskane z $1 \mathrm{~kg}$ paliwa w ciągu $1 \mathrm{~h}[\mathrm{kWh}$,

$W_{u}-$ wartość opałowa paliwa $[\mathrm{kJ} / \mathrm{kg}]$.

Sprawność instalacji C.O.:

$$
\dot{\eta}_{C . o .}=\dot{\eta}_{w} \cdot \dot{\eta}_{p} \cdot \dot{\eta}_{r} \cdot \dot{\eta}_{W e}
$$

gdzie: $\dot{\eta}_{\text {C.O. }}-$ sprawność instalacji C.O. [\%],

$\dot{\eta}_{w}$ - sprawność kotła [\%],

$\dot{\eta}_{p}-$ sprawność instalacji [\%],

$\dot{\eta}_{r}$ - sprawność regulacji [\%],

$\dot{\eta}_{w e}$ - sprawność wykorzystania ciepła [\%].

Ciepło przeniesione z pomieszczeń z $1 \mathrm{~kg}$ paliwa:

$$
Q_{p}=Q_{u} \cdot \dot{\eta}_{C . o .}
$$

gdzie: $Q_{p}$ - ciepło przeniesione z pomieszczeń z $1 \mathrm{~kg}$ paliwa [kWh].

Średnie zużycie paliwa:

$$
Z_{p s ́ r}=\frac{E}{Q_{u} \cdot \eta_{C . O}}
$$

gdzie: $Z_{p s s}-$ średnie zużycie paliwa $[\mathrm{kg}]$,

$E$ - zapotrzebowanie na energię [kWh/rok]. 
Tabela 2. Obliczenie zużycia paliwa

Table 2. Calculation of fuel consumption

\begin{tabular}{|c|c|c|c|}
\hline Rodzaj paliwa & Węgiel & Pelet & Jednostka \\
\hline Wartość opałowa & 29000 & 17500 & $\mathrm{~kJ} / \mathrm{kg}$ \\
\hline Ciepło uzyskane z $1 \mathrm{~kg} \mathrm{w}$ ciągu $1 \mathrm{~h}$ & 8,06 & 4,84 & $\mathrm{kWh}$ \\
\hline Sprawność instalacji C.O. & 73 & 80 & $\%$ \\
\hline$\bullet$ kocioł & 85 & 93 & $\%$ \\
\hline $\begin{array}{l}\text { - } \text { instalacja, } \\
\text { - regulacja, } \\
\text { - wykorzystanie ciepła } \\
\text { W każdym przypadku przyjęto } 95 \%\end{array}$ & 86 & 86 & $\%$ \\
\hline Ciepło przeniesione z pomieszczeń z 1 kg paliwa & 5,88 & 3,87 & $\mathrm{kWh}$ \\
\hline \multicolumn{4}{|c|}{ Zapotrzebowanie na energię } \\
\hline - pierwotną & \multicolumn{2}{|c|}{9548} & $\mathrm{kWh} / \mathrm{rok}$ \\
\hline - końcową & \multicolumn{2}{|c|}{10767} & $\mathrm{kWh} / \mathrm{rok}$ \\
\hline \multicolumn{4}{|c|}{ Średnie zużycie paliwa } \\
\hline $\begin{array}{l}\text { - dla energii pierwotnej } \\
\text { i sprawności C.O. }\end{array}$ & 1623 & 2466 & $\mathrm{~kg}$ \\
\hline - dla energii końcowej i sprawności kotła & 1572 & 2393 & $\mathrm{~kg}$ \\
\hline Całkowite zapotrzebowanie na ciepło & \multicolumn{2}{|c|}{7460,05} & $\mathrm{~W}$ \\
\hline $\begin{array}{l}\text { Zużycie paliwa przy }-20{ }^{\circ} \mathrm{C} \\
\text { (uwzględniając sprawność instalacji C.O.) }\end{array}$ & $\begin{array}{l}1,27 \\
\sim 31\end{array}$ & $\begin{array}{l}1,92 \\
\sim 46\end{array}$ & $\begin{array}{l}\mathrm{kg} / \mathrm{h} \\
\mathrm{kg} / \mathrm{d}\end{array}$ \\
\hline
\end{tabular}

Zużycie paliwa przy temperaturze $-20^{\circ} \mathrm{C}$ :

$$
Z_{p}=\frac{\frac{\phi}{W_{u}} \cdot 3600}{\dot{\eta}_{C . O .}}
$$

gdzie: $Z_{p}$ - zużycie paliwa przy temperaturze $-20^{\circ} \mathrm{C}[\mathrm{kg} / \mathrm{h}]$,

$\phi$ - projektowe obciążenie cieplne budynku [W].

Z obliczeń wynika (tab. 3), że zużycie węgla w tym wypadku powinno wynosić $1623 \mathrm{~kg}$ rocznie, a zużycie peletu $2466 \mathrm{~kg}$ rocznie. Średnia cena węgla $(29 \mathrm{MJ} / \mathrm{kg})$ w Rzeszowie wraz z dowozem to $750 \mathrm{zt} / \mathrm{t}$, a peletu $(17,5 \mathrm{MJ} / \mathrm{kg})$ $620 \mathrm{zł} / \mathrm{t}$.

Tabela 3. Obliczenie rocznych kosztów ogrzewania

Table 3. Calculation of annual heating costs

\begin{tabular}{|l|c|c|}
\hline \multicolumn{1}{|c|}{ Rodzaj paliwa } & Węgiel & Pelet \\
\hline Wartość opałowa & $29000 \mathrm{~kJ} / \mathrm{kg}$ & $17500 \mathrm{~kJ} / \mathrm{kg}$ \\
\hline Średnie zużycie & $1623 \mathrm{~kg}$ & $2466 \mathrm{~kg}$ \\
\hline Cena za tonę paliwa & $750 \mathrm{zł}$ & $620 \mathrm{zł}$ \\
\hline Roczny koszt ogrzewania & $1217,25 \mathrm{zł}$ & $1528,92 \mathrm{zł}$ \\
\hline
\end{tabular}




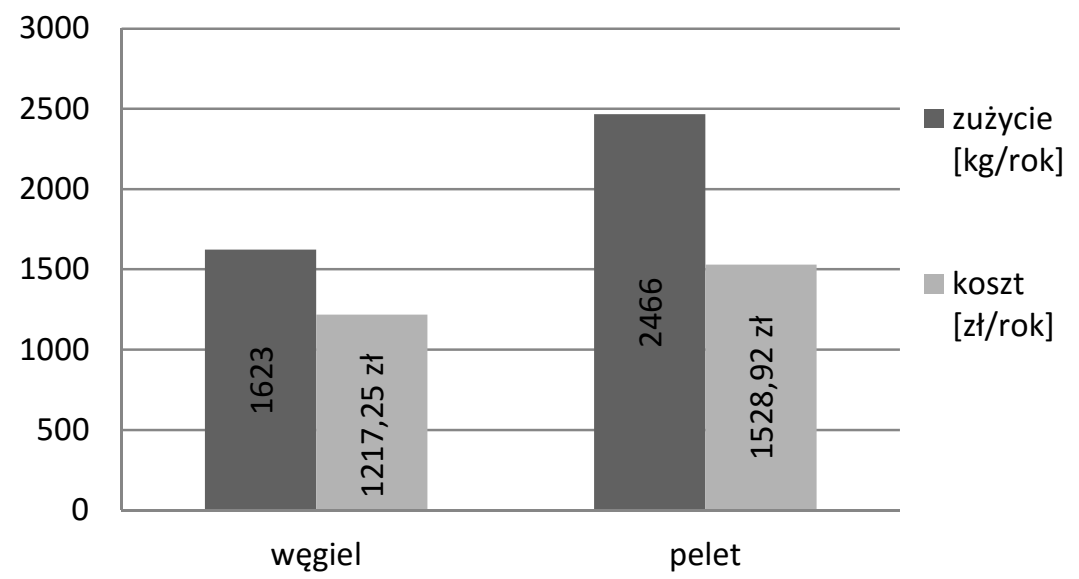

Rys. 3. Roczne zużycie oraz koszt węgla i peletu

Fig. 3. Annual consumption and the cost of coal and pellets

Na postawie obliczeń stwierdzono, że ogrzewanie węglem domu jednorodzinnego o powierzchni użytkowej $130 \mathrm{~m}^{2}$, jest tańsze o ponad $300 \mathrm{zł}$ od ogrzewania peletem (rys. 3) przy założonych właściwościach kalorycznych i cenowych paliw. Jeżeli zakupimy węgiel o mniejszej kaloryczności- tańszy, różnica ta będzie mniejsza. Jednak za tę cenę zanieczyszczamy środowisko i przyczyniamy się do powstawania smogu. Dlatego warto się zastanowić czy $25 \%$ kosztów więcej, to tak dużo, w porównaniu do czyściejszego powietrza.

\section{Podsumowanie}

Wykorzystanie energii znajdującej się w odpadach, roślinach czy drzewach jest niesamowitą alternatywą do ogrzania domu. Jednak duża część społeczeństwa, nie dostrzegła jeszcze korzyści z opalania biomasą. Większość z nas ogrzewa dom węglem, co według obliczeń jest średnio tańsze o $25 \%$ w porównaniu do peletu. Jednak spalanie węgla w piecach przydomowych to zagrożenie dla zdrowia człowieka. Piece te należą do tzw. źródeł niskiej emisji, ponieważ odprowadzające je kominy, które znajdują się na ok. 10 metrów nad ziemią w domach wolnostojących i ok. 20 metrów nad ziemią w kamienicach. Emitują bezpośrednio do atmosfery ok. 38\% cząstek stałych. Jak podają źródła ponad 33\% Polaków eksponowanych jest na działanie średnich rocznych stężeń pyłu zawieszonego PM10 wynoszących $40 \mu \mathrm{g} / \mathrm{m}^{3}$ lub więcej, a 97\% ludności Polski narażona jest na stężenia pyłu powyżej poziomu rekomendowanego przez WHO $\left(20 \mu \mathrm{g} / \mathrm{m}^{3}\right)$ [1]. Wdychanie zanieczyszczonego powietrza zwiększa zapadalność na różnego rodzaju choroby układu oddechowego, sercowo-naczyniowego. Dlatego warto się zastanowić nad zmianą paliwa z węgla na pelet. 


\section{Literatura}

[1] Adamkiewicz Ł.: Spalanie węgla w domowych piecach zagrożenia zdrowotne. Broszura Health and Environment Alliance (HEAL), Heal., czerwiec 2014.

[2] Budny J.: Energetyczna i ekologiczna ocena biomasy drzewnej na tle paliw konwencjonalnych. Praktyczne aspekty wykorzystania odnawialnych źródeł energy, Białystok 2005, s. 46-51.

[3] Dyrektywa 2001/77/WE z 27 września 2001 roku, w sprawie promocji produkcji energii elektrycznej w odnawialnych źródeł energii.

[4] Gołos P., Kaliszewski A.: Wybrane aspekty wykorzystania biomasy drzewnej do celów energetycznych. Leśne Prace Badawcze, Vol. 76 (1), 2015, s. 78-87.

[5] Grzybek A.: Potencjał biomasy możliwej do wykorzystania na produkcję pelet. „Czysta Energia” 6/2004.

[6] Juliszewski T., Ogrzewanie biomasą, Państwowe Wydawnictwo Rolnicze i Leśne, Poznań 2009.

[7] Lorenz U.: Skutki spalania węgla kamiennego dla środowiska przyrodniczego i możliwości ich ograniczania. Mat. Szkoły Eksploatacji Podziemnej. Sympozja i Konferencje nr 64, Wyd. Instytut GSMiE PAN, Kraków, s.97-112.

[8] Proszak-Miąsik, Boryło M.: Wykorzystanie odnawialnych źródeł energii w małych gospodarstwach rolnych. Czasopismo Inżynierii Lądowej, Środowiska i Architektury Politechniki Rzeszowskiej (JCEEA), t. XXXI, z. 61 (4/14), s.155-166.

[9] Proszak-Miąsik D., Nowak K., Rabczak S.: Wpływ współspalania biomasy z węglem na sprawność kotłów energetycznych. Czasopismo Inżynierii Lądowej, Środowiska i Architektury Politechniki Rzeszowskiej (JCEEA), t. XXXI, z. 61 (4/14), s. 144-154.

[10] Proszak-Miąsik D., Nowak K., Rabczak S.: Logistyka produkcji i dystrybucji roślin słomiastych, Logistyka 3/2015, s.1-6.

\section{EFFECT PELLETS OR CARBON? ECONOMIC ASPECTS OF THE CHOICE OF FUEL TO HEAT THE SINGLE-FAMILY BUILDING}

\section{S u m m a r y}

In In Poland, more and more users decide to support or total replacement of traditional fuels with alternative ones. The fuels that do not have harmful impact to the environment and are cheaper compare to traditional ones were selcted to calculation. Its all about renewable energy such as: sun, water, wind and processed solar energy absorbed by plants or biomass. This is not only related to the requirements for greenhouse gas and dust, which have restrictions, but also economic aspects. One can notice that the processed biomass pellets, chips or briquettes, obtained a lot of energy. This fuel is renewable, meaning that the carbon dioxide which is formed from the combustion process, absorb by plants in a given cycle, whereby a zero balance. But still a large group of people burn coal exclusively. Modern, automatic coal stoves can reach the combustion efficiency of $80-90 \%$, which makes for relatively low prices of coal in relation to other fuels cost in heating systems. To achieve high efficiency of heat generation is possible only with high coal quality. Disadvantage of coal combustion is smoke which affect to air as pollutant, and sa well as dust emissions, particulary sulfur dioxide, ash and slag. In this publication, compared the annual consumption of two fuels, wood pellets and coal were compared to heat a single family house with 
a usable area of $150 \mathrm{~m}^{2}$. The analysis of selected circumstances results some proposals on the profitability of the coal stove replacement on pellet one in case of financial and ecological effect.

Keywords: renewable fuel, fossil fuel, home heating costs, biomass

Przestano do redakcji: $12.12 .2015 \mathrm{r}$.

Przyjęto do druku: 1.03.2016 r.

DOI: $10.7862 / \mathrm{rb} .2016 .128$ 